they have been excluded from richer agricultural land by large landowners and commercial elites. Social factors also influenced the Irish potato famine of the mid-nineteenth century. Potatoes can feed a family well from a very small plot of land, improving offspring survival and thus driving population growth. Pushed onto marginal land by large landowners, Irish peasants nevertheless thrived by growing potatoes; they were desperately poor, but not starving. When the potato blight hit Ireland, the resultant starvation killed more than a million Irish people and led to the emigration of millions more.

In his account of the Irish famine, Reader offers the central message of the book. Eliminating extreme hunger and poverty is one of the United Nations' Millennium Development Goals, but the history of the potato shows us that truly eliminating poverty means much more than ensuring the security of food supplies and avoiding hunger; social equity is equally, if not more, important. Science on its own is no panacea for solving social ills.

Sandra Knapp is a plant taxonomist in the

Department of Botany, Natural History Museum, Cromwell Road, London SW7 5BD, UK.

e-mail: s.knapp@nhm.ac.uk

\title{
Building from the environment
}

\author{
Abundant Australia \\ The Australian Pavilion, 11th International \\ Architecture Exhibition, Venice \\ 14 September until 23 November 2008
}

Moving beyond the creation of iconic buildings, architects are looking to natural forms for inspiration by appropriating biological patterns, structures and mechanisms to engage with the landscape. At the 11th International Architecture Exhibition at this year's Venice Biennale, as part of Out There: Architecture Beyond Building, several countries will focus on science in their installations. Japan picks the theme of extreme landscapes for its pavilion, Denmark highlights ecology, Egypt chooses geometry and Spain looks to a future of 'paperless' design and construction.

The Australian pavilion displays 300 model exhibits from 180 architecture and design practices, and highlights the inspiration that can be found around us with designs inspired by the flora, fauna and environment of that whole continent.

The microscopic structures of scales on moth and butterfly wings inspired the duallayer, glazed facade on the Australian Museum's new Collections and Research Building, which will open in Sydney later this year. The cavity design of the panels will "insulate the building against extremes of temperature and humidity, and reduce traffic noise", says architectural practice Johnson Pilton Walker. Angled, dichroic glass within the panels seems to change colour as people walk past.

The Sydney-based French architect Frank Minnaërt asks how the

"We must conceive of architecture
in a different way from the Western
tradition based on a concept of
heroic domination of space."

functionality of biological membranes might be transposed into architecture, looking particularly at how organisms achieve maximum efficiency from minimal adaptation. His conceptual model Patternity comprises interacting

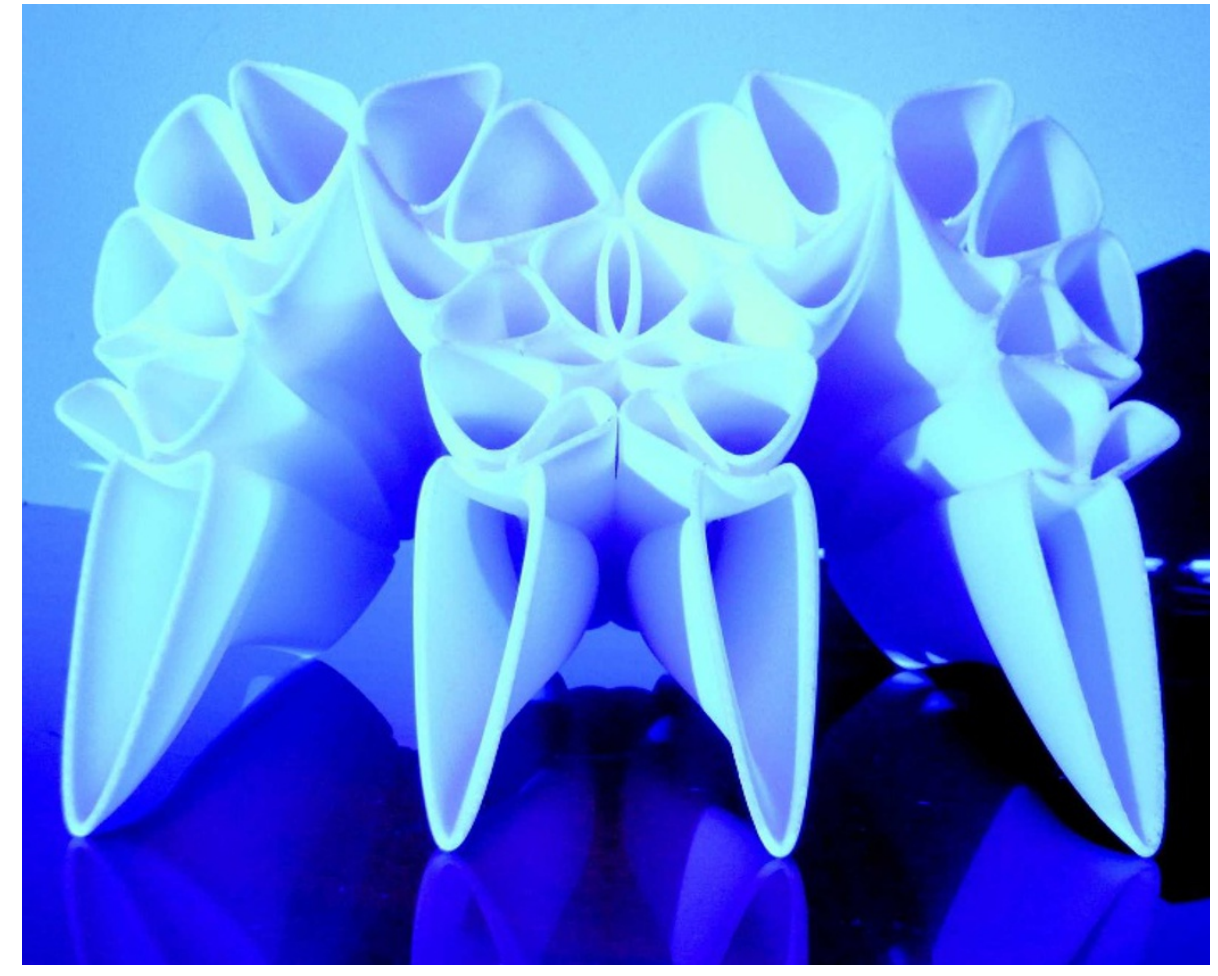

Frank Minnaërt's model Patternity highlights the potential of membranes to cool new buildings.

units through which selectively permeable thermal membranes, yet to be developed, might stabilize building temperatures throughout the year.

Some designers are inspired by natural processes, such as fire and erosion, that alter the Australian environment. "We must conceive of architecture in a different way from the Western tradition based on a concept of heroic domination of space," says John Nichols of Woodhead architects, who incorporated scorched timber into the newly opened Pinnacles Desert Discovery Centre in Western Australia.
Sunglasses for the Building, exhibited by spaceagency, is a light-hearted suggestion for providing shade for a beachside residential development under construction in Western Australia. "The screen detail was derived from images of nearby eroded limestone formations, and contributes to a unique sense of place," says practice director Michael Patroni.

These individual pavilions at the exhibition show that architectural responses to local environments can provide potent symbolism and functional solutions. As the exhibition's director Aaron Betsky states, "In a concrete sense, architecture is what allows us to be at home in the world."

Colin Martin is a writer based in London. e-mail:cmpubrel@aol.com 